\title{
Impact of estrogen and progesterone receptor expression on the clinical and molecular features of papillary thyroid cancer
}

\author{
Guia Vannucchi ${ }^{1}$, Simone De Leo ${ }^{2}$, Michela Perrino ${ }^{2}$, Stefania Rossi ${ }^{3}$, Delfina Tosi ${ }^{4}$, \\ Valentina Cirello ${ }^{5}$, Carla Colombo ${ }^{2}$, Gaetano Bulfamante ${ }^{3,4}$, Leonardo Vicentini ${ }^{6}$ \\ and Laura Fugazzola ${ }^{1,5}$ \\ ${ }^{1}$ Endocrine Unit, Padiglione Granelli, Fondazione IRCCS Ca' Granda, Via F. Sforza, 35, 20122 Milan, Italy, \\ ${ }^{2}$ Department of Clinical Sciences and Community Health, University of Milan, Milan, Italy, ${ }^{3}$ Division of Pathology, \\ San Paolo Hospital, Milan, Italy, Departments of ${ }^{4}$ Health Sciences and ${ }^{5}$ Pathophysiology and Transplantation, \\ University of Milan, Milan, Italy and ${ }^{6}$ Endocrine Surgery Unit, Fondazione IRCCS Ca' Granda, Milan, Italy
}

Correspondence should be addressed to G Vannucchi Email guiava@libero.it

\begin{abstract}
Background: Thyroid cancer is highly prevalent in women during the fertile age, which suggests a possible impact of hormonal and reproductive factors.

Methods: We studied the expression of estrogen receptor $\alpha$ (ER $\alpha$ or ESR1) and progesterone receptor (PR or PGR) in 182 female and male patients with papillary thyroid cancer and correlated it to clinical and molecular features.

Results: ER $\alpha$ and PR expression was found in 66.5 and $75.8 \%$ of patients respectively and was significantly correlated with larger tumor size and with a non-incidental diagnosis. Moreover, a trend toward a higher prevalence of local metastases was observed in ER- and PR-expressing tumors, which possibly indicates a more aggressive behavior. Interestingly, the occurrence of the 'receptor conversion' phenomenon, which has already been reported to have a negative prognostic effect in breast cancer, was demonstrated for the first time in thyroid tumors. Indeed, almost all of the ER $\alpha$-positive primary tumors analyzed had ER $\alpha$-negative metastatic lymph nodes. At the genetic analyses, $B R A F^{V 600 E}$ mutation was detected in $23.2 \%$ of the tumors and had a higher prevalence in larger tumors and in those with a stronger ER $\alpha$ or PR staining.

Conclusions: The whole of the findings reported in the present study argue for an association between ER $\alpha$ and PR sex hormone receptor expression and a more aggressive presentation. Although no impact on outcome was found, the evaluation of ER $\alpha$ and PR receptor expression could add insights into the biological behavior of tumors and could modify the follow-up, particularly in fertile women affected with persistent disease.
\end{abstract}

\section{Introduction}

In more developed countries, thyroid cancer is the second most frequent malignancy in women during the fertile age (1), which suggests a possible impact of hormonal and reproductive factors. Consistently, in the past few decades, epidemiological and experimental findings have indicated a possible role of estrogens in the development and progression of differentiated thyroid tumors $(2,3)$. It is known that estrogens can regulate thyroid cell proliferation by binding to both estrogen receptors (ERs), ER $\alpha$ (ESR1) and ER $\beta$ (ESR2), and displaying different effects on cell survival and proliferation. In particular, a proliferative and anti-apoptotic effect and a role in metastatization have
(C) 2015 European Society of Endocrinology Printed in Great Britain
Published by Bioscientifica Ltd. 
been shown for $\mathrm{ER} \alpha$, whereas $\operatorname{ER} \beta$ has a differentiative and pro-apoptotic action $(3,4)$. Upon activation by estradiol $\left(\mathrm{E}_{2}\right)$, ER translocates to the nucleus and activates gene transcription. In thyroid cancer cell lines, the proliferative effects of estrogen were found to be mediated through the regulation of genes involved in growth control, such as bcl-2, Bax, c-fos, E-cadherin, and vimentin (4, 5, 6). Alternatively, $\mathrm{E}_{2}$ activation leads to a 'non-genomic' action by ER, which includes a rapid activation of the intracellular ERK-1/2 and PI3K/Akt signaling pathways (7).

Several studies on ER expression have been performed in both normal and neoplastic thyroid tissues with extremely variable results, mostly because of the poor reproducibility of the methods used (revised in (8)). Nevertheless, strong evidence exists that $\mathrm{ER} \alpha$ expression is significantly greater in patients with various types of thyroid neoplasms than it is in normal controls, whereas ER $\beta$ is significantly less expressed in tumors than it is in normal thyroid tissues $(9,10)$. The increased expression of $\mathrm{ER} \alpha$ in thyroid cancer might influence the development and progression of the tumor, particularly during pharmacological and physiological conditions characterized by high circulating estrogen levels. Indeed, in a recent case-control study on a large population, it was shown that the risk of thyroid cancer is significantly correlated with early menarche and higher number of pregnancies (11), and we and others have demonstrated that thyroid cancers diagnosed during pregnancy are associated with a poorer outcome $(12,13,14)$. An increased risk of thyroid cancer has also been documented in women who have been treated with estrogen for gynecological reasons and in women who were taking oral contraceptive pills (15). Interestingly, estrogen metabolites and conjugates have been found to be significantly higher in women with well-differentiated thyroid cancer as compared to age-matched control women (16).

To define the possible role of estrogens in the development and progression of thyroid cancers, studies comparing the expression of ER in tumor tissues with the histopathological and clinical characteristics are warranted. To date, only two studies on T1 and T2 papillary thyroid cancers (PTCs) have shown a correlation between ER $\alpha$-positive and ER $\beta$-negative expression and worse histopathology data $(17,18)$. In terms of progesterone receptor (PR) concerns, only a few expression studies in thyroid tissues have been published $(13,19)$, and no data have yet been produced on the impact of ER $\alpha$ and PR expression on the disease outcome in PTCs.

Thus, the aim of the present study was to investigate the expression of ER $\alpha$ and PR in a large series of PTCs using immunohistochemistry and to correlate that expression to the clinical and molecular features and to the disease outcome.

\section{Patients and methods}

\section{Patients}

One hundred eighty-two consecutive patients (142 females, 40 males, mean age 47.9 , range 14-83) with available paraffin-embedded thyroid tumor tissue blocks were studied. In seven of them, neck metastatic lymph node tissue samples were also collected. Eighty-seven female patients (61\%) were diagnosed before menopause. All of the patients underwent total thyroidectomy that, for those with a preoperative diagnosis of malignancy, was associated with a pretracheal and paratracheal lymphadenectomy (levels VI-VII), and all have been treated and followed up in our university hospital. Patients with clinical and/or cytological suspicion of neck metastases were also submitted to mono- or bilateral laterocervical lymph node dissection. After surgery, patients were maintained on thyrotropin (TSH)-suppressive levothyroxine $\left(\mathrm{L}-\mathrm{T}_{4}\right)$ treatment unless disease remission was documented, and they were then shifted to lower doses, with an aim of reaching TSH levels between 0.5 and $1.0 \mathrm{mU} / 1$. The approval of the ethical committee was obtained for the present retrospective observational study.

\section{Tumor classification and outcome definition}

Tumors were classified and staged according to the thyroid malignancy World Health Organization classification AJCC Cancer Staging Manual, 7th edn (20). Only tumors with an extrathyroidal invasion (i.e., invasion of the thyroid capsule and/or lymph nodal or distant metastases) or with a diameter $>2 \mathrm{~cm}$ were submitted to radioiodine residue ablation, according to current guidelines (21). The criteria used to identify remission or persistent/ recurrent disease were based on the European and American guidelines for the management of differentiated thyroid cancer $(21,22)$ and have been previously reported in detail (23).

\section{$B R A F^{V 600 E}$ mutation analysis}

Neoplastic cells were obtained by laser microdissection from the tumor tissue of 151 patients with a diagnosis of PTC. DNA was extracted from microdissected tissues, and $B R A F^{V 600 E}$ mutation was analyzed by PCR amplification and direct sequencing, as previously described (24). 


\section{Immunohistochemical analysis of ER $\alpha$ and PR in tumor tissues}

Formalin-fixed paraffin-embedded tissue sections $(4 \mu \mathrm{m})$ were dewaxed in xylene and rehydrated in graded ethanol solutions. Antigen retrieval was obtained by incubating tissue sections at $100^{\circ} \mathrm{C}$ for $30 \mathrm{~min}$ in EDTA $0.05 \mathrm{M} \mathrm{pH}$ 8.0. Endogenous peroxidase block was performed by immersion of the slides in 3\% hydrogen peroxide. Sections were incubated for $30 \mathrm{~min}$ with the primary MAB ER $\alpha$ (clone 1D5, diluted 1:200) and PgR (clone 636, diluted 1:100), supported by Dako (Carpinteria, CA, USA). The reaction was detected by a Novolink Max polymer detection system (Novocastra Laboratories Ltd, Leica Microsystem, Nußloch, Germany), following manufacturer's instructions, using diaminobenzidine (DAB) as chromogen and incubating for $8 \mathrm{~min}$ at RT. One slide that included negative controls lacking the primary antibody was immunostained in the same batch. The sections were counterstained with hematoxylin and examined after dehydration and mounting. Scoring of immunoreactivity of ER $\alpha$ and PR expression was performed on a high-power field (X40) using a standard light microscope. Immunohistochemistry results were classified as absent expression, weak positivity when $<30 \%$ of the cells were stained, and strong positivity when $\geq 30 \%$ cells were stained.

\section{Statistical analysis}

Relations between discrete variables were evaluated by means of an $\chi^{2}$ test or $t$-test, as appropriate. Statistical significance was defined as $P<0.05$. All statistical analyses were performed using SPSS version 8.0 statistical package for Windows and MedCalc Software version 12.5.00 for Windows.

\section{Results}

\section{Clinical and histopathological features}

The clinical and histopathological characteristics of the enrolled patients are summarized in Table 1. In particular, the mean age at diagnosis was $47.9 \pm 14.5$ years and the tumor size was $15.6 \pm 11.3 \mathrm{~mm}$. About half of the patients (53.8\%) had a multifocal tumor, and the classical variant of papillary cancer was the most frequent histotype (80.9\%). An extrathyroidal extension was recorded in 66/182 (36.2\%) cases, and lymph node metastases were found at diagnosis in 63 patients (34.6\%). After a mean \pm S.D. follow-up of $73 \pm 37.5$ months, the disease was
Table 1 Clinical, histopathological, and molecular characteristics of patients.

\begin{tabular}{|c|c|}
\hline Characteristics & Whole group $(n=182)$ \\
\hline Age at diagnosis (mean \pm S.D.) & $47.9 \pm 14.5$ \\
\hline Incidental tumors $(n(\%))$ & $73(40.1)$ \\
\hline Tumor size (mm, mean \pm s.D. $)$ & $15.6 \pm 11.3$ \\
\hline \multicolumn{2}{|l|}{ Tumor extension $(n(\%))$} \\
\hline T1 & $105(57.7)$ \\
\hline $\mathrm{T} 2$ & $11(6)$ \\
\hline T3 & $63(34.6)$ \\
\hline T4 & $3(1.6)$ \\
\hline Multifocality & $98(53.8)$ \\
\hline \multicolumn{2}{|l|}{ Histological variants $(n(\%))$} \\
\hline Classical papillary & $152(80.9)$ \\
\hline Papillary-follicular variant & $26(13.8)$ \\
\hline Papillary sclerosant variant & $6(3.2)$ \\
\hline Oncocytic variant & $4(2.1)$ \\
\hline Autoimmunity & $32 / 133(24.1)$ \\
\hline Lymph-node metastases $(n(\%))$ & $63(34.6)$ \\
\hline \multicolumn{2}{|l|}{ Stage $(n(\%))$} \\
\hline I & $129(70.9)$ \\
\hline II & $4(2.2)$ \\
\hline III & $36(19.8)$ \\
\hline IV & $13(7.1)$ \\
\hline BRAF (V600E) mutation ( $n(\%))$ & $35 / 151(23.2)$ \\
\hline Outcome (persistence) $(n(\%))$ & 27/163 (16.6) \\
\hline
\end{tabular}

persistent or recurrent in $27 / 163(16.6 \%)$ patients. One female patient with persistent disease became pregnant, although contraindicated, and was followed during gestation. During pregnancy, her TSH levels were maintained and well suppressed (i.e., $<0.01 \mathrm{mU} / \mathrm{l}$ ). $\mathrm{T}_{4}$ was titrated according to the TSH levels, and minor dose adjustments were required but were limited to the first two trimesters of pregnancy. She showed a progressive increase in serum thyroglobulin ( $\mathrm{Tg}$ ) levels, from pre-pregnancy values of $33-73.2,108$, and $119 \mu \mathrm{g} / \mathrm{l}$ in the first, second, and third trimester respectively. Her serum $\mathrm{Tg}$ levels decreased to $60 \mu \mathrm{g} / \mathrm{l} 1 \mathrm{month}$ after delivery (Fig. 1).

\section{Immunohistochemical analysis of ER $\alpha$ and PR in tumor tissues}

ER $\alpha$ expression was found in $121 / 182$ cases (66.5\%), whereas PR expression was found in 138/182 cases (75.8\%), and there were no significant differences among sexes either for ER $\alpha$ or for PR. The staining was weak in 77/90 ER $\alpha$-positive female and 26/31 ER $\alpha$-positive male cases as well as in 70/109 PR-positive female and 15/29 PR-positive male cases, and it was strong in the remaining positive patients (data not shown). ER $\alpha$ and PR expression significantly correlated with tumor size, either in terms of the dimensions as a continuous variable $(P=0.002$ and $P<0.0001$ by $t$-test) or when dividing the tumors into 


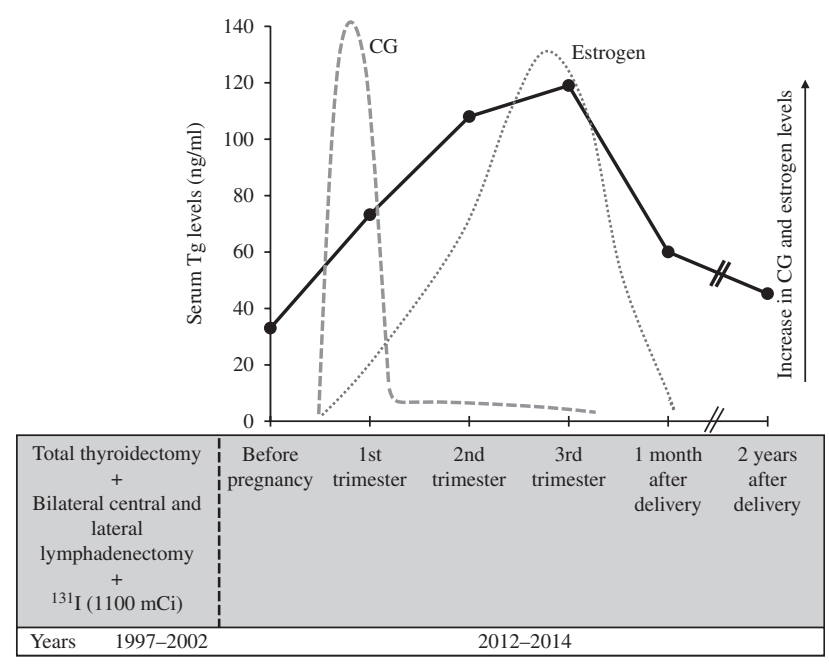

\section{Figure 1}

Serum thyroglobulin ( $\mathrm{Tg}$ ) levels in a female patient with papillary thyroid cancer (PTC) during the three trimesters of pregnancy and after delivery. Exemplificative hCG and estrogen trends during the normal singleton pregnancy are also shown.

three subgroups $(\leq 1,1-2$, or $>2 \mathrm{~cm}, P=0.006$ and $P=0.002$ by $\chi^{2}$ test) (Fig. 2A). Moreover, ER $\alpha$ and PR expression were more frequent in clinically evident tumors as compared to incidental cases $(P=0.0001$ for both) (Fig. 2B). The logistic regression analysis that was done using parameters that were significantly associated with $\mathrm{ER} \alpha$ and PR expression during univariate testing as input variables confirmed that $\mathrm{ER} \alpha$ and $\mathrm{PR}$ expression are independently associated with either larger tumor size (ER $\alpha$ : $P=0.027$; PR: $P=0.05)$ or incidental diagnosis $(\mathrm{ER} \alpha$ : $P=0.004$; PR: $P=0.0002$ ).

A non-statistically significant trend toward a higher prevalence of local metastases was observed in ER $\alpha$ - and PR-expressing tumors (Fig. 3A). On the other hand, neither extrathyroidal extension nor outcome significantly correlated with $\mathrm{ER} \alpha$ and PR expression (Fig. 3B and C). Finally, the prevalence of both ER $\alpha$ and PR expression did not significantly differ in pre- and postmenopausal age $(P=0.16$ and $P=0.54$ respectively) (data not shown).

In seven cases, we had the opportunity to compare the $\mathrm{ER} \alpha$ and PR expression between the primary tumor and metastatic neck lymph node tissue. In five patients that had a positive staining for $\mathrm{ER} \alpha$ in the primary tumor, $\mathrm{ER} \alpha$ was not expressed in the metastatic tissues, whereas one patient was negative for $\mathrm{ER} \alpha$ in both the primary and metastatic tissues, and another patient was negative in the primary tumor and focally expressed ER $\alpha$ in the lymph node. On the contrary, PR was expressed in both the primary tumor and lymph nodes in 6/7 cases, and the metastatic tissue was negative in one case (Fig. 4A, B and C).

\section{$B R F^{V 600 E}$ molecular analysis}

$B R A F^{V 600 E}$ mutation was detected in 35/151 (23.2\%) tissues. Of note, the prevalence of $B R A F^{V 600 E}$ was significantly different when the tumors were divided according to their diameters: $\leq 1 \mathrm{~cm}$ : $9.5 \%, 1-2 \mathrm{~cm}$ : 29.3\%, $>2 \mathrm{~cm}: 36.4 \%(P=0.004)$. BRAF ${ }^{V 600 E}$ prevalence was similar among patients in remission or with persistent/relapsing disease (25.2 vs $20.8 \%, P=0.85$ ) (data not shown). ER $\alpha$ - and PR-positive cases tended to harbor, although not at a statistically significant level, the $B R A F^{V 600 E}$ mutation more frequently than the negative cases did. Interestingly, when the patients were divided according to the degree of staining, a trend showed a correlation between the intensity of staining for both receptors and $B R A F^{V 600 E}$ mutation, which was statistically significant for PR expression $(P=0.03)$ (Fig. 5).
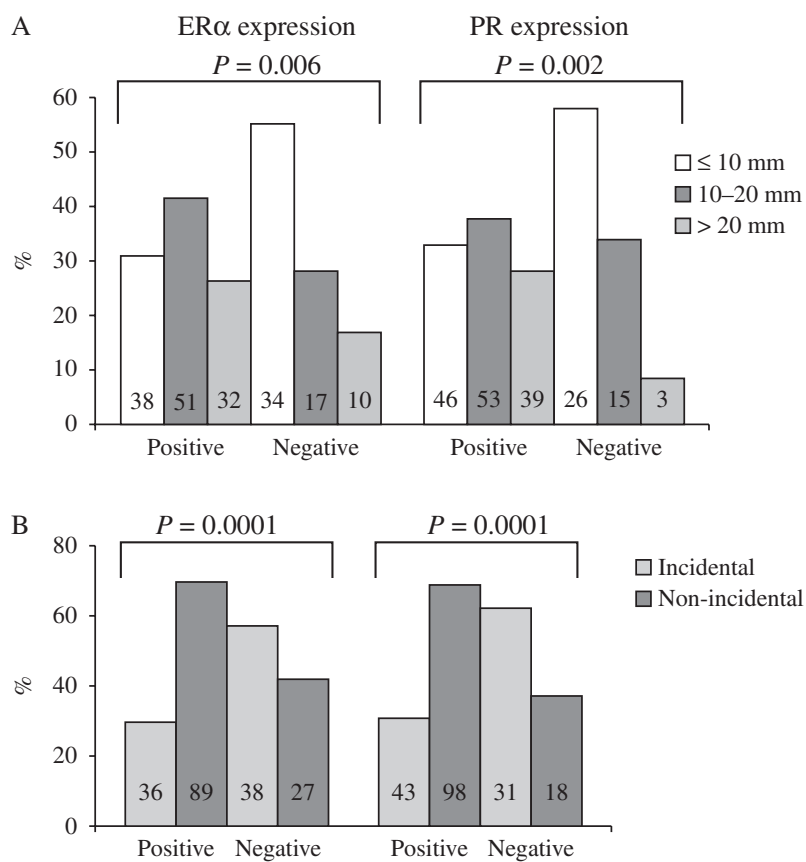

Figure 2

(A) The frequency of ER $\alpha$ and PR expression according to tumor size. (B) The frequency of ER $\alpha$ and PR expression according to diagnosis. 

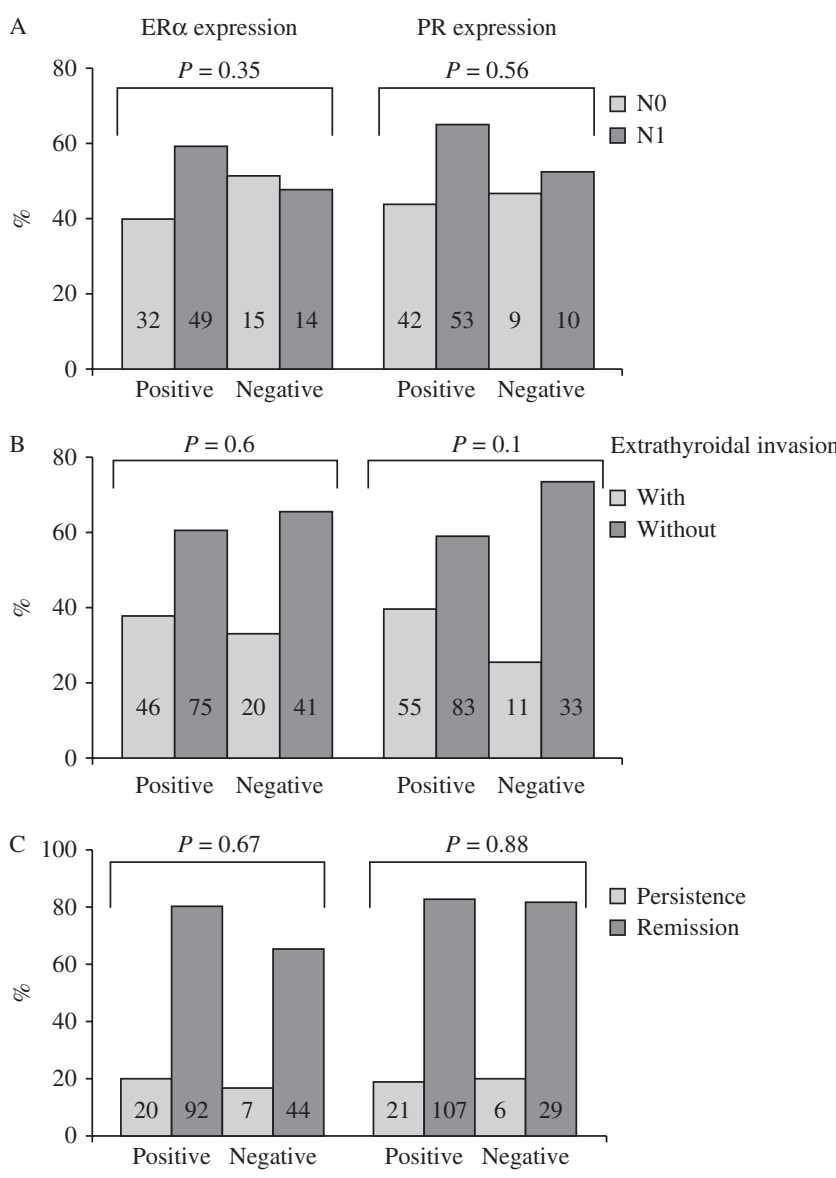

\section{Figure 3}

(A) ER $\alpha$ and PR expression and lymph node metastases at diagnosis. (B) ER $\alpha$ and PR expression and extrathyroidal invasion. (C) ER $\alpha$ and PR expression and outcome.

\section{Discussion}

In the present study, $\mathrm{ER} \alpha$ and $\mathrm{PR}$ were found to be frequently expressed in differentiated thyroid cancers (66 and 76\% respectively). This prevalence is higher than that reported in some previous studies $(13,17,25,26)$, although the available data are scanty, controversial, and were obtained in more limited series. Indeed, some authors found an up-regulation of ER $\alpha$ in PTCs when using immunohistochemistry $(19,27,28)$, whereas others did not find any difference in ER $\alpha$ expression in thyroid tumors with respect to normal tissues, or they observed a lack of ER expression in thyroid neoplasms $(8,25,26)$. Most of these discrepancies are likely a result of the methodologies used. On the other hand, recently published data have clearly demonstrated, by means of different approaches (such as laser-capture microdissection, magnetic immunoprecipitation, realtime PCR, and western blot), the expression of ER $\alpha$ in thyroid tumor tissues but not in normal thyroid tissues (9). In the present series, tumors with a positive ER and PR staining were significantly and independently associated with a larger tumor size and were more frequently

\begin{tabular}{|ccccc}
\hline A & ER $\alpha$ tumor & ER $\alpha$ LN & PR tumor & PR LN \\
\hline$\# 1$ & + & - & + & + \\
$\# 2$ & + & - & + & + \\
$\# 3$ & - & + & + & - \\
$\# 4$ & + & - & + & + \\
$\# 5$ & + & - & + & + \\
$\# 6$ & - & - & + & + \\
$\# 7$ & + & - & + & + \\
\hline
\end{tabular}
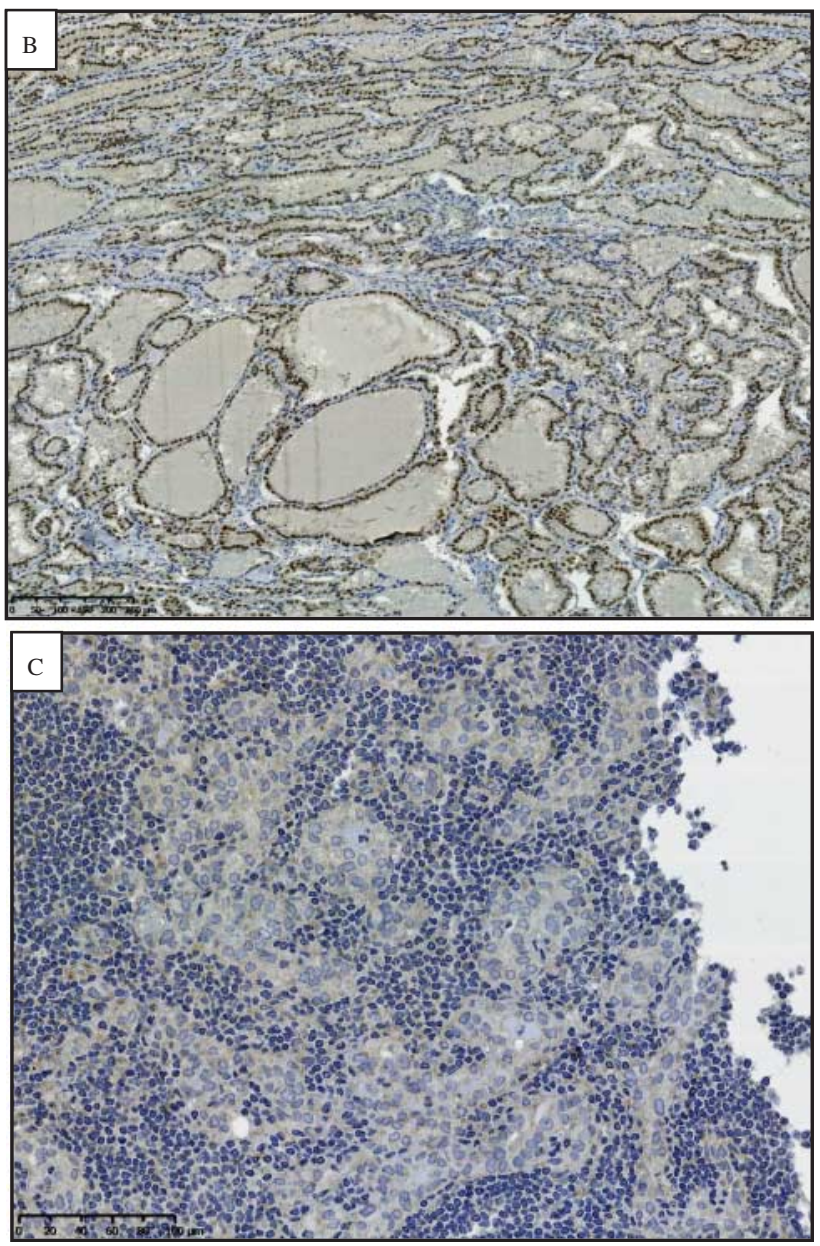

\section{Figure 4}

(A) The phenomenon of 'receptor conversion' between the primary differentiated thyroid tumor and the metastatic lesion in seven cases of primary papillary thyroid cancer and lymph node metastases (LN). (B) ER $\alpha$-positive staining in a thyroid tumor tissue. (C) ER $\alpha$-negative staining in a neck lymph node metastasis. 


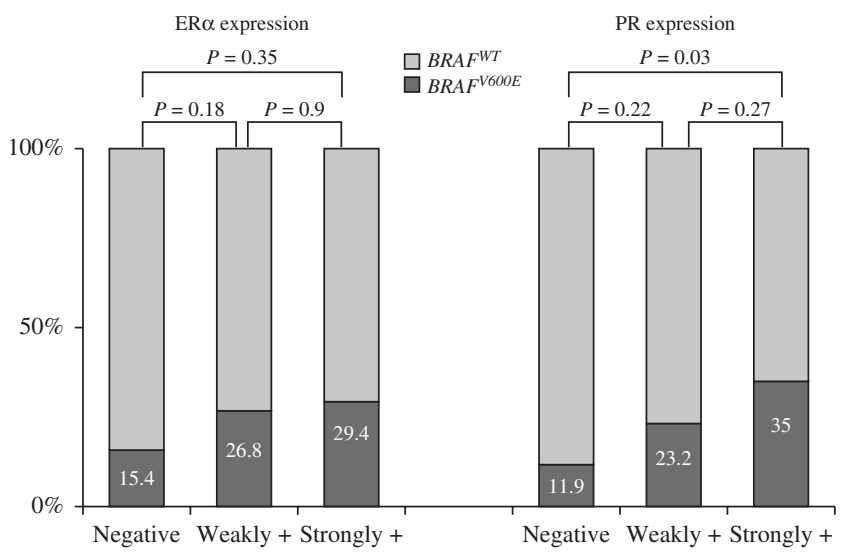

\section{Figure 5}

Sex hormone receptor expression (ER $\alpha$ and $\mathrm{PR}$ ) and $B R A F^{V 600 E}$ mutation.

non-incidental at diagnosis, which is consistent with previous data obtained in T1 and T2 thyroid tumors (17, 18). Moreover, a trend toward a higher prevalence of local metastases was observed in ER- and PR-expressing tumors, which possibly indicates a more aggressive behavior. Despite this worse presentation, no impact on outcome was recorded, likely as a consequence of the highly effective diagnostic and therapeutic tools available for this neoplasm and its recognized benign course. The comparative study of primary tumors and metastatic lymph nodes allowed us to demonstrate for the first time in thyroid tumors the occurrence of the 'receptor conversion' phenomenon for ER $\alpha$ (29). Indeed, almost all of the ER $\alpha$-positive primary tumors analyzed had ER $\alpha$ negative metastatic lymph nodes. On the contrary, the same pattern of PR expression was found in primary tumors and lymph nodal metastases. Although they are preliminary, these data are consistent with those reported in breast cancer for both ER and PR. In particular, several studies have shown that the receptor status of breast metastases may differ from that of the primary tumor, with the primary tumor being positive and metastases being negative in most cases $(30,31)$. This finding may be explained by either the clonal selection of less-differentiated receptor negative cells during the metastatic process or the occurrence of a genetic drift during tumor progression (32). Nevertheless, the definite role of receptor conversion in thyroid cancer remains to be clarified, seeing as the data reported here are novel and preliminary. Still, considering that receptor conversion in breast cancer has been associated with a negative prognostic effect, more studies on this topic would be of interest (33).

The present study is the first to compare ER $\alpha$ and PR expression not only with the histopathological data but also with outcome and with the molecular analysis of $B R A F^{V 600 E}$. This genetic alteration was significantly more prevalent in larger tumors, although there was no correlation with outcome, as has been previously reported for our population (34). Interestingly, $B R A F^{V 600 E}$ mutation was found to be more common in tumors that positively stained for $\mathrm{ER} \alpha$ and $\mathrm{PR}$, although the relatively limited number of cases did not allow it to reach statistical significance. This finding is of particular interest, because it is known that in benign and malignant thyroid cells, $\mathrm{E}_{2}$ can stimulate the Ras/Raf/MAP kinase signaling pathway via its membrane-bound receptor (35). Thus, an additive action on this pathway, which is critical for the proliferation and propagation of thyroid cancer, could be hypothesized for tumors that are harboring both the ER expression and the $B R A F^{V 600 E}$ mutation.

The whole of the findings reported in the present study argue for an association between sex hormone receptor expression and a more aggressive presentation. It is possible to speculate that, at least in females, this finding could also a result of the action of sex hormones on ER $\alpha$ and PR-expressing tumors, as has been suggested in previous studies that reported a worse outcome for thyroid cancer when it was diagnosed during pregnancy $(12,13,14)$. Accordingly, it is well documented in benign and malignant thyroid carcinoma cells that $\mathrm{E}_{2}$ stimulates growth and amplifies its growth-promoting effect by the up-regulation of $\operatorname{ER} \alpha(2,6)$. In this context, we had the opportunity to follow up a woman with persistent PTC who showed a progressive increase of serum Tg levels during pregnancy, with a maximum value just before delivery and a progressive reduction in the postpartum period. The possible contribution of the placenta to the $\mathrm{Tg}$ elevation seems to be excluded by data that demonstrate the absence of either Tg mRNA or Tg as a protein in the placenta, decidua, or ovaries in any stage of pregnancy (36). On the other hand, the Tg rise could be correlated to the increase of chorionic gonadotropin (CG) that occurs during the first trimester of pregnancy, which represents an important growth factor for thyrocytes. Nevertheless, in our patient, the most relevant increase of serum $\mathrm{Tg}$ occurred in the second and third trimester of pregnancy, paralleling the estrogen increase. Thus, we are prompted to speculate an estrogen rather than a CG effect.

In conclusion, the present study confirmed that the expression of $\mathrm{ER} \alpha$ and $\mathrm{PR}$ is frequent in thyroid tumor 
tissues, and it is significantly associated with larger tumor size and, consistently, with a non-incidental diagnosis. Moreover, a trend toward a higher prevalence of local metastases and a higher prevalence of $B R A F^{V 600 E}$ mutations were observed in ER- and PR-expressing tumors, which possibly indicates a more aggressive behavior. Although no impact on the outcome of the disease was observed, the evaluation of sex hormone receptors could add insights into the biological behavior of tumors, and it could modify follow-up, particularly in fertile women affected with persistent disease. In addition, the phenomenon of receptor conversion, which has been reported here in thyroid tumors for the first time, could represent another issue to consider in follow-up, and further studies are needed in order to understand its effect on thyroid tumor prognosis. Finally, the finding of a strong expression of ER in some thyroid tumors suggests the need to evaluate the possible usefulness of an antiestrogen therapy in selected cases to attenuate the growth-promoting effects of $\mathrm{E}_{2}$.

\section{Declaration of interest}

The authors declare that there is no conflict of interest that could be perceived as prejudicing the impartiality of the research reported.

\section{Funding}

This research did not receive any specific grant from any funding agency in the public, commercial or not-for-profit sector.

\section{References}

1 Franceschi S \& Wild CP. Meeting the global demands of epidemiologic transition - the indispensable role of cancer prevention. Molecular Oncology 20137 1-13. (doi:10.1016/j.molonc.2012.10.010)

2 Manole D, Schildknecht B, Gosnell B, Adams E \& Derwahl M. Estrogen promotes growth of human thyroid tumor cells by different molecular mechanisms. Journal of Clinical Endocrinology and Metabolism 200186 1072-1077.

3 Zeng Q, Chen G, Vlantis A, Tse G \& van Hasselt C. The contributions of oestrogen receptor isoforms to the development of papillary and anaplastic thyroid carcinomas. Journal of Pathology 2008214 425-433. (doi:10.1002/path.2297)

4 Dong W, Zhang H, Li J, Guan H, He L, Wang Z, Shan Z \& Teng W. Estrogen induces metastatic potential of papillary thyroid cancer cells through estrogen receptor $\alpha$ and $\beta$. International Journal of Endocrinology 20132013 941568. (doi:10.1155/2013/941568)

5 Zeng Q, Chen GG, Vlantis AC \& van Hasselt CA. Oestrogen mediates the growth of human thyroid carcinoma cells via an oestrogen receptorERK pathway. Cell Proliferation 200740 921-935. (doi:10.1111/ j.1365-2184.2007.00471.x)

6 Vivacqua A, Bonofiglio D, Albanito L, Madeo A, Rago V, Carpino A, Musti AM, Picard D, Andò S \& Maggiolini M. 17 $\beta$-estradiol, genistein, and 4-hydroxytamoxifen induce the proliferation of thyroid cancer cells through the G protein-coupled receptor GPR30. Molecular Pharmacology 200670 1414-1423. (doi:10.1124/mol.106.026344)

7 Kumar A, Klinge CM \& Goldstein RE. Estradiol-induced proliferation of papillary and follicular thyroid cancer cells is mediated by estrogen receptors $\alpha$ and $\beta$. International Journal of Oncology 201036 1067-1080. (doi:10.3892/ijo_00000629)

8 Santin AP \& Furlanetto TW. Role of estrogen in thyroid function and growth regulation. Journal of Thyroid Research 20112011875125. (doi:10.4061/2011/875125)

9 Di Vito M, De Santis E, Perrone GA, Mari E, Giordano MC, De Antoni E, Coppola L, Fadda G, Tafani M, Carpi A et al. Overexpression of estrogen receptor- $\alpha$ in human papillary thyroid carcinomas studied by laser-capture microdissection and molecular biology. Cancer Science 2011102 1921-1927. (doi:10.1111/j.1349-7006.2011.02017.x)

10 Chen GG, Vlantis AC, Zeng Q \& van Hasselt CA. Regulation of cell growth by estrogen signaling and potential targets in thyroid cancer. Current Cancer Drug Targets 20088 367-377. (doi:10.2174/ 156800908785133150)

11 Xhaard C, Rubino C, Cléro E, Maillard S, Ren Y, Borson-Chazot F, Sassolas G, Schvartz C, Colonna M, Lacour B et al. Menstrual and reproductive factors in the risk of differentiated thyroid carcinoma in young women in France: a population-based case-control study. American Journal of Epidemiology 2014180 1007-1017. (doi:10.1093/ aje/kwu220)

12 Vannucchi G, Perrino M, Rossi S, Colombo C, Vicentini L, Dazzi D, Beck-Peccoz P \& Fugazzola L. Clinical and molecular features of differentiated thyroid cancer diagnosed during pregnancy. European Journal of Endocrinology/European Federation of Endocrine Societies 2010 162 145-151. (doi:10.1530/EJE-09-0761)

13 Messuti I, Corvisieri S, Bardesono F, Rapa I, Giorcelli J, Pellerito R, Volante M \& Orlandi F. Impact of pregnancy on prognosis of differentiated thyroid cancer: clinical and molecular features. European Journal of Endocrinology/European Federation of Endocrine Societies 2014 170 659-666. (doi:10.1530/EJE-13-0903)

14 Shindo H, Amino N, Ito Y, Kihara M, Kobayashi K, Miya A, Hirokawa M \& Miyauchi A. Papillary thyroid microcarcinoma might progress during pregnancy. Thyroid 201424 840-844. (doi:10.1089/thy.2013.0527)

15 Ron E, Kleinerman RA, Boice JD Jr, LiVolsi VA, Flannery JT \& Fraumeni JF Jr. A population-based case-control study of thyroid cancer. Journal of the National Cancer Institute 198779 1-12.

16 Zahid M, Beseler CL, Hall JB, LeVan T, Cavalieri EL \& Rogan EG. Unbalanced estrogen metabolism in ovarian cancer. International Journal of Cancer 2014134 2414-2423. (doi:10.1002/ijc.28565)

17 Magri F, Capelli V, Rotondi M, Leporati P, La Manna L, Ruggiero R, Malovini A, Bellazzi R, Villani L \& Chiovato L. Expression of estrogen and androgen receptors in differentiated thyroid cancer: an additional criterion to assess the patient's risk. Endocrine-Related Cancer 201219 463-471. (doi:10.1530/ERC-11-0389)

18 Magri F, Capelli V, Gaiti M, Villani L, Zerbini F, La Manna L, Rotondi M $\&$ Chiovato L. ER- $\alpha$ and ER- $\beta$ expression in differentiated thyroid cancer: relation with tumor phenotype across the TNM staging and peri-tumor inflammation. Endocrine 2015. In press. (doi:10.1007/ s12020-014-0457-x)

19 Kansakar E, Chang YJ, Mehrabi M \& Mittal V. Expression of estrogen receptor, progesterone receptor, and vascular endothelial growth factor-A in thyroid cancer. American Surgeon 200975 785-789 discussion 789 .

20 Edge S, Byrd DR, Compton CC, Fritz AG, Greene FL, Trotti A (Eds). American Joint Committee on Cancer 2012 TNM classification of malignant tumours. In AJCC Cancer Staging Handbook, 7th edn. New York: Springer Verlag.

21 American Thyroid Association (ATA) Guidelines Taskforce on Thyroid Nodules and Differentiated Thyroid Cancer, Cooper DS, Doherty GM, Haugen BR, Kloos RT, Lee SL, Mandel SJ, Mazzaferri EL, McIver B, Pacini F et al. Revised American Thyroid Association management guidelines for patients with thyroid nodules and differentiated 
thyroid cancer. Thyroid 200919 1167-1214. (doi:10.1089/thy. 2009.0110)

22 Pacini F, Schlumberger M, Dralle H, Elisei R, Smit JW, Wiersinga W \& European Thyroid Cancer Taskforce . European consensus for the management of patients with differentiated thyroid carcinoma of the follicular epithelium. European Journal of Endocrinology/European Federation of Endocrine Societies 2006154 787-803. (doi:10.1530/ eje.1.02158)

23 Perrino M, Vannucchi G, Vicentini L, Cantoni G, Dazzi D, Colombo C, Rodari M, Chiti A, Beck-Peccoz P \& Fugazzola L. Outcome predictors and impact of central node dissection and radiometabolic treatments in papillary thyroid cancers $<$ or $=2 \mathrm{~cm}$. Endocrine-Related Cancer 2009 16 201-210. (doi:10.1677/ERC-08-0119)

24 Fugazzola L, Mannavola D, Cirello V, Vannucchi G, Muzza M, Vicentini L \& Beck-Peccoz P. BRAF mutations in an Italian cohort of thyroid cancers. Clinical Endocrinology 200461 239-243. (doi:10.1111/ j.1365-2265.2004.02089.x)

25 Vaiman M, Olevson Y, Sandbank J, Habler L, Zehavi S \& Kessler A. Are estrogen receptors $\alpha$ detectable in normal and abnormal thyroid tissue? European Archives of Oto-Rhino-Laryngology 2010267 1753-1757. (doi:10.1007/s00405-010-1269-0)

26 Vaiman M, Olevson Y, Habler L, Eviatar E, Zehari S, Sandbank J \& Kessler A. The estrogen receptors in the papillary carcinoma of the thyroid gland. Oncology Research 201018 537-540. (doi:10.3727/ 096504010X12767359113802)

27 Yane K, Kitahori Y, Konishi N, Okaichi K, Ohnishi T, Miyahara H, Matsunaga T, Lin JC \& Hiasa Y. Expression of the estrogen receptor in human thyroid neoplasms. Cancer Letters 199484 59-66. (doi:10.1016/ 0304-3835(94)90358-1)

28 Tavangar SM, Monajemzadeh M, Larijani B \& Haghpanah V. Immunohistochemical study of oestrogen receptors in 351 human thyroid glands. Singapore Medical Journal 200748 744-747.

29 Holdaway IM \& Bowditch JV. Variation in receptor status between primary and metastatic breast cancer. Cancer 198352 479-485.
(doi:10.1002/1097-0142(19830801)52:3<479::AID-CNCR282052 $0317>3.0 . \mathrm{CO} ; 2-\mathrm{O})$

30 Amir E, Ooi WS, Simmons C, Kahn H, Christakis M, Popovic S, Kalina M, Chesney A, Singh G \& Clemons M. Discordance between receptor status in primary and metastatic breast cancer: an exploratory study of bone and bone marrow biopsies. Clinical Oncology 200820 763-768. (doi:10.1016/j.clon.2008.08.005)

31 Hoefnagel LD, van de Vijver MJ, van Slooten HJ, Wesseling P, Wesseling J, Westenend PJ, Bart J, Seldenrijk CA, Nagtegaal ID, Oudejans $\mathrm{J}$ et al. Receptor conversion in distant breast cancer metastases. Breast Cancer Research 201012 R75. (doi:10.1186/bcr2645)

32 Kuukasjärvi T, Karhu R, Tanner M, Kähkönen M, Schäffer A, Nupponen N, Pennanen S, Kallioniemi A, Kallioniemi OP \& Isola J. Genetic heterogeneity and clonal evolution underlying development of asynchronous metastasis in human breast cancer. Cancer Research 199757 1597-1604.

33 Hoefnagel LD, Moelans CB, Meijer SL, van Slooten HJ, Wesseling P, Wesseling J, Westenend PJ, Bart J, Seldenrijk CA, Nagtegaal ID et al. Prognostic value of estrogen receptor $\alpha$ and progesterone receptor conversion in distant breast cancer metastases. Cancer 2012118 4929-4935. (doi:10.1002/cncr.27518)

34 Fugazzola L, Puxeddu E, Avenia N, Romei C, Cirello V, Cavaliere A, Faviana P, Mannavola D, Moretti S, Rossi S et al. Correlation between B-RAFV600E mutation and clinico-pathologic parameters in papillary thyroid carcinoma: data from a multicentric Italian study and review of the literature. Endocrine-Related Cancer 200613 455-464. (doi:10.1677/erc.1.01086)

35 Derwahl M \& Nicula D. Estrogen and its role in thyroid cancer. Endocrine-Related Cancer 201421 T273-T283. (doi:10.1530/ ERC-14-0053)

36 Moravej A, Jeddi-Tehrani M, Salek-Moghaddam AR, Dokouhaki P, Ghods R, Rabbani H, Kazemi-Sefat GE, Shahbazi M \& Zarnani AH. Evaluation of thyroglobulin expression in murine reproductive organs during pregnancy. American Journal of Reproductive Immunology 201064 97-103. (doi:10.1111/j.1600-0897.2010.00827.x)

Received 15 January 2015

Revised version received 1 April 2015

Accepted 10 April 2015 